\title{
A JUDICIALIAÇÃO DAS RELAÇÕES SOCIAIS E A ADOÇÃO DOS MEIOS CONSENSUAIS DE SOLUÇÃO DOS CONFLITOS
}

\author{
Geovana Faza da Silveira Fernandes ${ }^{1}$ \\ Mônica Micaela de Paula ${ }^{2}$
}

\section{RESUMO}

Este artigo reflete sobre a judicialização das relações sociais na vigência do Estado social, suas consequências no fenômeno da litigância e sobre a necessidade de adotarmos meios consensuais de solução de conflitos como imperativo da cidadania. O ponto de partida é o paradigma do Estado social, passando pela democratização e realocação do Poder Judiciário como depositário das demandas da sociedade e garantidor dos direitos fundamentais, justificando a ampliação de seu campo de atuação. Trataremos ainda da instrumentalização do processo e de sua função de pacificação, ligando-se aos meios não-adversariais positivados sob os influxos da terceira onda de acesso à justiça.

Palavras-chave: judicialização; relações sociais; cidadania; acesso à justiça; meios consensuais.

\section{THE JUDICIALIZATION OF SOCIAL RELATIONSHIPS AND THE ADOPTION OF ALTERNATIVE CONFLICTS RESOLUTIONS}

\begin{abstract}
This article reflects on the judicialization of social relationships under the rule of the Welfare State, its consequences on the phenomenon of litigation and on the need of alternatives disputes resolutions. The bottom line is the paradigm of the Welfare State, through the democratization and reallocation of the Judicial Power as depositary of social demands and guardian of fundamental rights, justifying the expansion of its role. We will also approach the instrumentalization of the process and its pacification mission, linking to the non-adversarial processos positived under the influence of the third wave of "Access to Justice" movement.
\end{abstract}

Keywords: judicialization; social relationships; citzenship; access of justice; alternative dispute resolution.

\section{INTRODUÇÃO}

\footnotetext{
${ }^{1}$ Mestranda em Direito pela Universidade Católica de Petrópolis, pesquisadora visitante na Boston College Law, Pós-graduada em Direito Público pela PUC/Minas, Bacharel em Direito pela Universidade Federal de Juiz de Fora, instrutora de mediação certificada pelo CNJ e pelo CJF. Diretora do Centro Judiciário de Conciliação da Justiça Federal, Subseção Judiciária de Juiz de Fora/MG. E-mail: geovanafaza@gmail.com. https://orcid.org/0000-0002-2031-9735.

${ }_{2}^{2}$ Mestranda em Direito pela Universidade Católica de Petrópolis. Pós-graduada em Direito Processual pela Universidade Federal de Juiz de Fora, Especialista em Planejamento e Gerenciamento em Saúde pela Universidade Federal de Juiz de Fora. Pós-graduanda em Direito de Família e Sucessões. E-mail: monicamicaelaadv@gmail.com. https://orcid.org/0000-0002-3200-7923.
} 
A Constituição Federal de 1988 constitui marco da participação mais ativa do Poder Judiciário no processo democrático. A ampliação de sua atuação, com a previsão constitucional de instrumentos jurídicos, princípios e normas que buscam garantir uma justiça mais célere e distributiva, demonstra preocupação com a salvaguarda do Estado democrático de direito.

O pano de fundo que orienta este trabalho reside na socialização do processo no Brasil, na judicialização das relações sociais, na mudança de paradigma do Estado social para o modelo democrático de direito, e como essas estruturas impactam na forma de pensar a realização da garantia do acesso ao Judiciário, para posteriormente, tratarmos da importância dos meios consensuais de resolução dos conflitos.

Nos itens 2 e 3 trataremos do Estado social e do fenômeno da judicialização das relações sociais, que passam a exigir um fortalecimento do Poder Judiciário como concretizador dos direitos sociais, impactando no papel do processo. O redimensionamento do acesso à justiça, junto com diversos outros fatores, deságua num excesso de litigância que abarrota o Judiciário, refletindo na prestação jurisdicional, que se torna morosa e ineficiente.

Com a morosidade, o abarrotamento do Poder Judiciário, acrescidos à complexidade das relações sociais, surge a necessidade de outros meios de resolução de conflitos que não os heterocompositivos. Esses temas serão tratados nos itens 4, 5 e 6, que abordarão o fenômeno da instrumentalidade do processo, seus escopos e a adoção de meios consensuais, não só como forma de conferir celeridade e eficácia à prestação jurisdicional, mas também como meio de legitimação da práxis judiciária, ao ampliar a participação das partes e proporcionar oportunidades de diálogo direcionado ao consenso, empoderamento e ao fortalecimento da cidadania.

\section{O PARADIGMA DO ESTADO SOCIAL E A JUDICIALIZAÇÃO DAS RELAÇÕES SOCIAIS}

Pensemos sobre as razões de ser do Poder Judiciário: resolver conflitos aplicando o direito objetivo ao caso concreto, zelar pela constitucionalidade do arcabouço normativo, pelo controle dos atos do Estado frente às leis vigentes e podemos dizer também da sua função de estabelecer a clareza, a coerência da ordem jurídica e sua efetividade no plano da sociedade. As funções precípuas, todavia, nem sempre convivem de forma pacífica com o modelo de Estado adotado e com o princípio da separação dos poderes, o que pode ser inferido da 
tendência de incursão judicial em searas antes pertencentes a outros sistemas, como o econômico, político e social.

Essa ampliação da atuação judicial, em termos mundiais, passa pela ideia de judicialização das relações sociais, que tem sua origem no século XIX, com a Revolução Industrial (VIANNA, 1999, p.16). Com os padrões trabalhistas insalubres daquela época, passou-se a exigir do Estado uma postura menos liberal para que a dignidade do trabalhador fosse minimamente respeitada. Desse modo, no final do século XIX e início do século XX, em alguns países desenvolvidos, começaram a surgir movimentos em prol dos direitos dos trabalhadores, o que contribuiu para o delineamento dos Estados de bem-estar social, que encontraram na legislação garantidora de direitos sociais mínimos uma forma de realizar uma justiça social mais igualitária e distributiva.

Naquele momento histórico, medidas de assistência familiar, habitacional, programas sanitários, dentre outros, passaram a fazer parte de ordenamentos jurídicos de algumas nações mais desenvolvidas, como meios para diminuir as desigualdades entre os cidadãos ou garantir o mínimo de condição para uma vida mais digna.

O paradigma social, pois, ligou-se ao Estado providencial, àquele que toma as rédeas de outros sistemas em prol de programas futuros de realização de misteres sociais, como os mencionados acima. Nos dizeres de Mauro Cappelletti, citado por Werneck Vianna (1999, p.16), a promoção de programas sociais "consiste em prescrever programas de desenvolvimento futuros, promovendo-lhes execução gradual, ao invés de simplesmente escolher, como é típico da legislação clássica, entre 'certo e errado', ou seja, entre o caso ‘justo' e o ‘injusto"”.

Como não poderia deixar de ser, essa postura induziu à inclusão no direito de noções como justiça, para fins de realização do ideal de igualdade e maior dignidade. E se são necessárias prestações positivas do próprio Estado para garantir esses ideais, a liberdade individual moderna recuou para dar lugar à justiça social.

Assistimos, então, a limitações impostas à liberdade individual e à autodeterminação, privilegiando-se a 'inclusão' do economicamente desfavorecido. Não há como refutar a invasão do Estado e do direito nas searas individuais. Esse contexto faz com que considerações de ética social infiltrem-se "em regiões do direito que, até então, se limitavam a garantir a autonomia privada", conforme reflete Habermas (1997, p. 134).

Com o Pós-guerra, foi necessária uma revisão da política do Welfare State, não obstante a positivação internacional de direitos fundamentais do homem, assentados na ideia 
de dignidade da pessoa humana, e sua replicação para constituições nacionais. A justiça social deveria conviver com a liberdade privada, restringida com a publicização de relações da esfera privada.

Na esteira dessa nova virada paradigmática, vem à tona um modelo de Estado que deve ser balizado pelos direitos humanos e pelo respeito à liberdade de autodeterminação e de autolegislação dos cidadãos. É o Estado constitucional democrático ou Estado democrático de direito.

A democracia, ao lado dos direitos humanos, passa a ser a preocupação central de muitos países que viveram os tempos sombrios do totalitarismo. Segundo Boaventura de Sousa Santos, pensar a democracia como ruptura positiva na trajetória de uma sociedade implica abordar seus elementos culturais, o que permite abrir espaço para a concepção procedimental de democracia e suas dimensões societárias (2002, p. 52).

Todavia, não podemos transplantar acriticamente o suceder histórico das formas de Estado das nações desenvolvidas do norte e seu impacto na judicialização das relações sociais aos Estados subdesenvolvidos do sul. Isso porque não há concomitância histórica de modelos estatais entre os Estados desenvolvidos e os subdesenvolvidos.

Enquanto os Estados hoje desenvolvidos assistiam a um progresso industrial e científico (no decorrer dos séculos XVIII e XIX), o Brasil experimentava o ápice do colonialismo, assentado em uma sociedade escravocrata. No início do século XX, enquanto florescia o Welfare State, o Brasil iniciava a República que deveria ter como principal foco a inclusão daqueles que tinham acabado de se libertar da escravidão. Sucessivas ditaduras também deixaram à margem o empoderamento e a emancipação dos cidadãos e a própria realização da dignidade da pessoa humana. A Declaração Universal dos Direitos do Homem, de 1948, somente ecoou no Brasil na década 1980. E, enquanto as nações mais desenvolvidas já deixavam de lado o modelo de Estado social para o democrático constitucional, o Brasil ainda engatinhava rumo ao Estado de bem-estar.

Não adiantava somente estabelecer o regime democrático, outorgando aos cidadãos o direito de voto, e achando que com isso a cidadania já estava garantida. O Brasil da década de 1980 precisava urgentemente de políticas públicas garantidoras dos direitos humanos que a Carta de 1988 positivou, como um conjunto de normas programáticas cujo telos é diminuir as desigualdades sociais e garantir a dignidade dos cidadãos, de forma ampla. Entretanto isso não bastava. Era necessário estabelecer garantias de cumprimento por parte do Executivo e do 
próprio Legislativo, que, diante do gigante que teriam que enfrentar, se viram ineficientes e insuficientes.

Assim, a partir do final da década de 1980, ante a ineficiência estatal na consecução dos direitos sociais, o Poder Judiciário passou a assumir-se como poder político atuando mais fortemente em três campos: no garantismo de direitos, no controle da legalidade e dos abusos de poder e na judicialização da política (SANTOS, 2002). A Constituição Federal de 1988, portanto, constitui marco no cenário democrático que se descortinava para a plena consagração do Judiciário como instrumento concretizador da justiça social.

O próprio direito passou a ter cunho mais social do que liberal, decorrente desse modelo de Estado, que precisou publicizar relações que antes eram consideradas somente do domínio privado, para então instrumentalizar o próprio Estado para a consecução dos ideais sociais.

Podemos dizer que o Estado colocou o direito nos rumos da justiça social. Quando sua face executiva não consegue se desincumbir do dever de zelar pelos direitos que constitucionalmente lhe cabe realizar, sua face judicatória entra em cena para garantir a eficácia desses mesmos direitos.

O sopro de democratização e de expansão do Estado social, que plasmou na Constituição Federal um arcabouço de direitos sociais que dependem de prestações positivas do Estado para sua efetivação, fez-se sentir não só no robustecimento da Justiça, mas impactou diretamente nos escopos do próprio Judiciário e, portanto, do seu principal instrumento, que é o processo.

O Poder Judiciário passou a ser depositário das demandas da sociedade, especialmente de setores mais fragilizados, tendo sido chamado, ainda, a cumprir papel de relevo político, na legitimação da democracia (SANTOS, 2002), principalmente do modelo brasileiro.

Para esse desiderato, o Poder Judiciário precisou adotar maior protagonismo no cenário de construção do Estado, intervindo nas políticas socioeconômicas para suprir as carências de efetividade dos direitos sociais. Mesmo diante do processo econômico neoliberal adotado pelo Brasil a partir da década de 1990, o Estado-juiz não se desincumbiu desse mister, considerando o déficit de realização dos direitos básicos dos cidadãos há quase trinta ano na Carta Constitucional, cabendo a ele, ainda, o papel de tutor de direitos fundamentais, o que justificaria a 'judicialização da política'. Não devemos perder de vista que essa 
judicialização, dentro de limites razoáveis, propicia maior efetividade da democracia no contexto pátrio.

Podemos falar em judicialização das relações sociais, e, fazendo referência à filosofia harbermasiana, à invasão do direito na esfera do mundo da vida, que se justifica na medida em que permite menor tensão entre facticidade e validade, ou seja, entre o mundo dos fatos, a realidade tal como a sentimos, e as pretensões de validade das interferências do sistema (Estado, poder econômico, burocracia) no mundo dos relacionamentos, da integração social, da comunicação, do viver do homem em sociedade.

A judicialização das relações, por sua vez, implica a submissão ao Poder Judiciário das expectativas de direito e pretensões dos cidadãos, que passaram a ter amplo acesso formal. Essa abertura do acesso à Justiça, buscada pelo conhecido Projeto Florença e suas ondas renovatórias (CAPPELLETTI, 1988), é responsável pelo redimensionamento do Poder Judiciário, tanto em termos físicos quanto de atuação, uma vez que passou a ser chamado a ocupar lugares simbólicos, na perspectiva da justiça e do escopo social do direito em relação à solução de litígios.

Acrescente-se que a garantia da inafastabilidade do controle jurisdicional (art. $5^{\circ}$, inciso XXXV, da CF), a possibilidade de assistência judiciária gratuita, a facilitação do acesso à justiça também fazem parte do cenário garantidor e concretizador dos direitos fundamentais. Esses aspectos fazem parte de um contexto muito amplo de realização dos ideais democráticos, no qual também está inserida a judicialização da política e das relações sociais.

\section{A JUDICIALIZAÇÃO DAS RELAÇÕES SOCIAIS E SEU IMPACTO NA CONSTRUÇÃO DA CIDADANIA}

As relações sociais e as políticas públicas vêm passando por um processo de invasão do direito e do Judiciário para a concretização de ideais sociais e democráticos, como tratado. Todavia, os efeitos dessa invasão são controversos, em razão dos limites nada claros nos quais o Judiciário atua.

Habermas entende que o avanço demasiado do direito e do Judiciário sobre as relações pode ser prejudicial à sociedade. Defende que, em certa medida, essa regulamentação é necessária até para resguardar a liberdade do cidadão e protegê-lo do excesso de colonização do mundo da vida pelo sistema. Entretanto, invasão em demasia pode acarretar 
um esvaziamento da cidadania, com o desempoderamento do cidadão e a construção de uma sociedade passiva e dependente de um assistencialismo estatal amparador e não inclusivo.

Sem ignorar os avanços que já obtivemos em termos democráticos, certo é que o Brasil ainda finca raízes nas terras de um Estado social mal acabado, onde podemos assistir a desigualdades gritantes, que precisam ser equacionadas por meio da efetivação de direitos básicos dos cidadãos, que se vêm desempoderados por uma mentalidade ditatorial reinante até o final da década de 1980, e que depois foi substituída por uma postura paternalista e assistencialista, que desencoraja a autonomia e autodeterminação.

O desenvolvimento retardatário do capitalismo no Brasil, fazendo com que a democracia seja, ainda, pouco elaborada, demanda do direito e do Poder Judiciário a assunção de papéis que desbordariam de suas atribuições típicas sob uma ótica liberal e positivista. Conforme leciona de Adriana Orsini (2016, p. 62), o direito, sob a perspectiva do Estado contemporâneo,

não está substituindo a estruturação democrática, pautada no associativismo e mobilização da sociedade civil, porque está ocupando uma espécie de vazio. A longa vigência do regime militar desregulamentou a vida social, desestimulou a solidariedade $\mathrm{e}$ incentivou o individualismo. Nessa concepção, a atuação do Poder Judiciário, ao invés de gerar cidadania passiva e alijar os cidadãos do processo democrático, ' pode se constituir, dependendo dos operadores sociais, em uma pedagogia para o exercício das virtudes cívicas'.

Nesse ponto, o direito e o Poder Judiciário, ao ocuparem um espaço antes vazio, passam a ser também responsáveis pelo fortalecimento da cidadania e pela construção de espaços de participação democrática. Luiz Werneck Vianna (1999, p. 22-23) já afirmara no final da década de 1990, que

em torno do Poder Judiciário vem-se criando, então uma nova arena pública,
externa ao circuito clássico 'sociedade civil - partidos - representação -
formação da vontade majoritária', consistindo em ângulo perturbador para a
teoria clássica da soberania popular. Nessa nova arena, os procedimentos
políticos de mediação cedem lugar aos judiciais, expondo o Poder Judiciário
a uma interpelação direta de indivíduos, de grupos sociais e até de partidos
(...) em um tipo de comunicação em que prevalece a lógica dos princípios,
do direito material, deixando-se para trás as antigas fronteiras que separavam
o tempo passado, de onde a lei geral e abstrata hauria seu fundamento, do
tempo futuro, aberto à infiltração do imaginário, do ético e do justo.

Podemos afirmar que a projeção do Judiciário em vários aspectos da vida social, no cenário contemporâneo, advém de complexos processos sociais, nacionais e internacionais, assim como das transformações sociais operantes após a segunda guerra, da declaração dos direitos 
humanos, da necessidade de implementação de ações visando à igualdade material, da limitação das liberdades públicas no decorrer da ditadura militar, que impôs uma visão hegemônica e imobilizando da sociedade ${ }^{3}$, dentre outros fatores. Esse diagnóstico é assente. Conforme reflete Werneck Vianna (1999, p. 23), restauram-se ideias segundo as quais

O avanço irresistível da igualdade poderia provocar o esvaziamento dos ideais e das práticas da liberdade, entendendo-se, contemporaneamente, que a invasão do direito, visível tanto na judicialização da política e das relações sociais, quanto na positivação dos direitos fundamentais, teria o "efeito de desestimular a face libertária e reivindicatória da cidadania social".

Estamos diante de um paradoxo: ao mesmo tempo em que o direito e o Poder Judiciário avançam sobre outros sistemas como decorrência da necessidade de conferir eficácia e concretude aos direitos sociais e à própria cidadania e democracia, há, por outro lado, como efeito perverso dessa invasão, um esvaziamento da participação dos cidadãos no próprio processo de efetivar tais direitos. É uma substituição da atuação dos cidadãos, em muitos casos, pela mão do Estado. Como diz Werneck (1999, p. 23), tira-se do terreno da sociedade civil ações emancipadoras, o que pode conduzir a uma "cidadania passiva de clientes, em nada propícia a uma cultura cívica e às instituições da democracia”. Busca-se a igualdade material sem o reforço da cidadania ativa. Ou seja, outorga-se ao Estado o poderdever de oferecer aos cidadãos condições dignas de vida, de trabalho, de moradia, saúde, cultura, mas sem o dever de investir em políticas públicas de emancipação. Há a redução dos cidadãos ao estatuto de indivíduos-clientes de um Estado providencial (VIANNA, 1999, p.24).

Ao rever o trabalho 'Judicialização da Política e das Relações Sociais no Brasil', Luiz Werneck Vianna e os outros autores ${ }^{4}$ pontuam que da guerra veio a motivação para que as constituições trouxessem em seu bojo um "núcleo dogmático", na expressão de Habermas, "explicitando valores fundamentais a obrigar o poder soberano" a realizar esse mesmo núcleo,

\footnotetext{
${ }^{3}$ Conforme concepções de Warat, para quem os cidadãos foram 'castrados' por essa hegemonia e imposição ditatorial, tornando-se representantes de uma cultura do imobilismo, e que fizeram com que não sentissem necessidade de "confrontar a realidade instituída, não expondo os poderes e a política aos conflitos que os desestabilizam porque, em razão da desmobilização, incapacidade de organização e ausência de desejo, esses sujeitos não conseguem tornar o político um espaço simbólico sem proprietários". Luis Alberto Warat, apud Adriana de Sena Orsini (2014, p. 63).

${ }^{4}$ Em 1999 Luiz Werneck Vianna e outros autores publicaram a obra "A judicialização da política e das relações sociais no Brasil", fruto de uma pesquisa realizada no final da década de 1990 acerca da judicialização das relações e das políticas públicas, como bem diz o título. VIANNA, Luiz Werneck; BURGOS, Marcelo Baumann; SALLES, Paula Martins. Dezessete anos de judicialização da política. Tempo Social, revista de sociologia da USP, v. 19, n.2. Tempo soc. v.19 n.2 São Paulo nov. 2007. Disponível em: 〈http://www.scielo.br/pdf/ts/v19n2/a02v19n2>. Acesso em: 19/05/2017.
} 
ao mesmo tempo dogmático e fundamental para a realização da dignidade da pessoa humana. E, mesmo anos depois, ainda se vislumbra o estilo centralizador estatal que não pode ser ignorado e que é fruto de "processos que se têm verificado ao longo da afirmação da vida democrática do país e de inovações institucionais de caráter pontual” (2007, p. 45).

A tendência a essa centralização tem origem em demandas dos movimentos sociais e da sociedade civil em geral. Esses processos "manifestam-se na criação de agências públicas de âmbito nacional, como o Sistema Único de Saúde (SUS), paradigma dominante em termos de políticas sociais, que já exerce influência na montagem de outras redes de intervenção, como a da educação" (VIANNA, 2007, p. 45).

A revisão e atualização da pesquisa conclui que houve uma mudança silenciosa nas relações entre a União e a sociedade civil, mas não houve políticas concretas de empoderamento e emancipação dos cidadãos. O robustecimento das políticas sociais tem levado a uma “ expansão da burocracia, cuja ação pode vir a tolher, se não for limitada por meios de controle democráticos, a livre movimentação da sociedade civil, em uma estatolatria doce, quase invisível, justificada por sua destinação social” (2007, p. 7).

Portanto, com essa marca legada na Constituição Federal de 1988, o Poder Judiciário é colocado na situação de um legislador implícito nas hipóteses de omissão dos demais poderes. E esse cenário impactou não só na necessidade de "realocação de lugares simbólicos" (ORSINI, 2014, p. 63) para o direito e para os juízes, mas principalmente no manejo do próprio instrumento de realização do direito que é o processo.

\section{IMPACTOS DA JUDICIALIZAÇÃO DAS RELAÇÕES SOCIAIS NO PAPEL INSTRUMENTAL DO PROCESSO}

O contexto pós-segunda guerra gerou a idealização do paradigma do Estado social, que defende o protagonismo judicial com vistas a exercer atividade compensadora dos déficits de igualdade material entre os cidadãos e a fortalecer a ideia do processo como relação jurídica e instrumento de realização da justiça e bem-estar social, com escopos políticos, sociais e econômicos. Nesse cenário, surgiram tendências processuais socializadoras que conduziram ao fortalecimento do Poder Judiciário, acarretando um esvaziamento do papel das partes e condução quase que maciça do processo pelo julgador. Essa socialização chegou ao ápice com o Projeto Florença, que serviu de base para os movimentos reformistas 
posteriores $^{5}$. As principais preocupações do projeto eram o problema do acesso dos indivíduos mais pobres à Justiça, bem como uma decisão justa e efetiva.

$\mathrm{O}$ direito de acesso à justiça é frequentemente considerado como um direito social (CAPPELLETTI, 1988, p. 15). A postura do Estado de bem-esta, como visto nos itens anteriores, trouxe fortes repercussões no sentido de trazer o direito para o centro da vida social, tirando-o de uma perspectiva puramente liberal e de garantia dos direitos afetos às liberdades primárias.

O movimento socializante, que enfatizou a figura do juiz protagonista, retirando das partes seu 'empoderamento' na condução do processo, assistiu a um arrefecimento com a mudança de paradigma do Estado social para o Estado democrático de direito, trazendo à luz a tensão entre posturas sociais e liberais que ainda se faz presente no dimensionamento processual e nos escopos do processo.

No Brasil, o escopo dos direitos sociais se impregnou no processo, transformando-o em instrumento de realização de justiça. Desde a década de 1990, entretanto, a ideologia processual socializante foi sofrendo degenerações sob o influxo de ideais neoliberais, preocupados com a eficiência, a celeridade e o custo. A morosidade processual passou a ser foco da política judiciária nacional a partir da Emenda Constitucional 45/2004, que alçou a direito fundamental a duração razoável do processo.

A instrumentalidade do processo reforçou-se, ora com tendências socializantes, ora com tendências liberais, tendentes a equacionar a necessidade de resguardo dos direitos e garantias fundamentais com o imperativo de celeridade e eficiência.

Essa instrumentalidade do processo parte da ideia de meio para proporcionar um fim maior: a garantia e efetividade dos direitos. Para Cândido Rangel Dinamarco (2000, p. $372 / 373)$

falar em instrumentalidade do processo ou em efetividade significa, no contexto, falar dele como algo posto à disposição das pessoas com vistas a fazê-las mais felizes (ou menos infelizes), mediante a eliminação dos conflitos que as envolvem, com decisões justas. Mais do que um princípio, o acesso à justiça é a síntese de todos os princípios e garantias do processo, seja a nível constitucional ou infraconstitucional, seja em sede legislativa ou

\footnotetext{
${ }^{5}$ O Projeto Florença, coordenado por Mauro Cappelletti, consistiu no mais abrangente projeto de pesquisa multidisciplinar sobre os sistemas jurídicos de países dos cinco continentes. Ao todo participaram 23 países voluntários. Representou o ápice do movimento de socialização do processo e visou diagnosticar os principais obstáculos de acesso à justiça e os motivos da ineficiência do aparato dos Judiciários para condução adequada e célere dos processos de solução de litígios. Na introdução do livro "Acesso à Justiça" (1988), Cappelletti e Garth esclarecem que o ensaio se destina a servir de introdução geral aos volumes da série Acesso à Justiça do "Projeto Florença", que possui seis tomos. Para os condutores da pesquisa empírica, o objetivo do relatório é o de "delinear o surgimento e desenvolvimento de uma abordagem nova e compreensiva dos problemas que esse acesso apresenta nas sociedades contemporâneas" $(1988$, p. 8).
} 
doutrinária e jurisprudencial. Chega-se à ideia do acesso à justiça, que é o polo metodológico mais importante do sistema processual na atualidade, mediante o exame de todos e de qualquer um dos grandes princípios.

Assistimos a um aumento exacerbado do demandismo, correlacionado a diversos fatores complexos: ineficiência estatal, descumprimento das leis, facilidade de acesso à justiça, generalização do exercício de direitos e ampliação dos meios de tutela, criação de novas unidades jurisdicionais competentes para pequenas causas, desigualdades sociais, deficiências nos resultados de políticas públicas, etc.

Esse excesso de litígios, que em parte demonstra que o acesso formal à justiça, também deságua em uma série de consequências nada positivas para o fortalecimento da democracia. É um paradoxo que tem que ser contornado: garante-se o acesso quase que irrestrito, mas a capacidade do Judiciário, com seus novos papéis no preenchimento de espaços antes não juridicizados e absorvendo a reivindicação de novos atores (ORSINI, 2014, p. 63), não absorve adequadamente a demanda, tornando-o incapaz de dar real e efetiva solução aos conflitos que lhes são levados em tempo razoável.

Todos esses fatores impactam no próprio direito processual. Embora o objetivo precípuo desse ramo do direito guarde íntima relação com sua função de servir de mecanismo de resolução de litígios, há quem diga que a jurisdição deva se revestir de novas funções e escopos. Se à jurisdição são atribuídas outras funções além da função de aplicar o direito ao caso concreto, ao processo também deverão ser lançados outros olhares que não somente o de composição de litígios. Conforme leciona Dinamarco, a noção de processo é ontologicamente finalística ou teleológica porque o processo só se aplica pelo seu fim e até meados do século XX preocupava-se mais com a compreensão e conceituação dos seus institutos do que com a própria definição de quais são os fins do processo (DINAMARCO, 2003).

O sistema processual possui três missões, a jurídica, segundo a qual o sistema processual serve como instrumento para a realização do direito objetivo em caso de litígio; a política, voltada à realização de garantias de justiça e liberdade, e a social, voltada à contribuição para a convivência pacífica dos jurisdicionados. Dinamarco explora essas três missões transcendentais, denominando-as de escopos da jurisdição. Cada um se relaciona a objetivos que devem ser alcançados pelo processo. São escopos do sistema processual: sociais, que dizem relação à pacificação social esperada de um ordenamento jurídico e à educação através do exercício da jurisdição, que deve servir para chamar a população para que ela, conhecendo seus direitos, possam trazê-los à apreciação do Judiciário; políticos, que se relacionam com a influência 
política que o ordenamento exerce nas relações do Estado com o cidadão; e, por fim, o escopo jurídico, que é a realização do direito material.

Para ele, "todo instrumento, como tal, é meio; e todo meio só é tal e se legitima em função dos fins a que se destina”. É um raciocínio teleológico, ou seja, que inclui os propósitos norteadores do processo e "das condutas dos agentes estatais que o utilizam" (DINAMARCO, 2003, p. 149).

Desse modo, o processo deve ser manejado para que o próprio ordenamento jurídicoprocessual seja eficiente a ponto de realizar os direitos subjetivos dos cidadãos. Com fundamento nessas concepções finalísticas, o processo passa a ser visto como instrumento de altos misteres estatais: realização da justiça, pacificação, atuação do direito material, instrumento de realização da cidadania e fortalecimento da democracia. Seu manejo deve ser coerente com seus escopos, sem desbordar dos limites constitucionais das garantias processuais, resumidas no due processo of Law, e sem subverter a separação dos poderes.

É fato que esses limites estão longe de serem bem delimitados. Com esses escopos insuflados, com a judicialização das relações sociais e ineficiência das políticas públicas, temos assistido a um excesso de litigiosidade. Basta olharmos para o 'Justiça em Números', pesquisa elaborada pelo Conselho Nacional de Justiça, que indica que fechamos 2015 com o astronômico número de, aproximadamente, 102 milhões de processos em tramitação.

Reflete Maria Tereza Sadek que o "descomunal número de processos que ingressa através da porta de entrada do Poder Judiciário encontra meandros que tornam distante o vislumbre da porta de saída" (2014, p. 60). Há, portanto, outro paradoxo: temos demandas demais, com uma porta escancarada, e, ao mesmo tempo, acesso de menos. Mas, como assim?

O excesso de acesso pode descambar para um 'não-acesso' na medida em que abarrota o Judiciário com demandas de determinados setores da sociedade ou do próprio Estado, dificultando sua atuação onde a celeridade e eficiência são necessárias. Esse excesso de litígios não condiz com o acesso universal e igualitário a todos os cidadãos, mas, olhando de perto os dados coletados pelo 'Justiça em Números', vemos que a larga porta de entrada do Poder Judiciário atrai determinado tipo de litigante e "desencoraja ou se fecha para a grande massa de indivíduos incapazes de manejar instrumentos de efetivação de seus direitos, produzindo um paradoxo: demandas demais e demandas de menos" (SADEK, 2014, p. 60).

O tipo de litigante que abarrota o Poder Judiciário: o próprio Estado, por meio de sua sistemática desobediência às leis, principalmente às normas programáticas insertas na $\mathrm{CF} / 88$, e pelo elevado número de execuções fiscais; os litigantes habituais que, em razão de grande 
volume de demandas, tiram dessa posição vantagens processuais como experiência, conhecimentos dos estratagemas e meandros legais, diluição dos custos pela várias demandas, possibilidade de influenciar a construção da jurisprudência ${ }^{6}$.

Então, esse descomunal número de processos que, a primeira vista poderia encetar uma conclusão a respeito da universalização real de acesso, na verdade estreita a porta de entrada e de saída, fazendo com que o verdadeiro acesso formal e substancial não se configure como possibilidade de "inclusão e de construção da cidadania" para grande parte dos brasileiros. Seria um cenário de excesso de acesso que gera um não acesso para parte da população (SADEK, 2014, p. 60) ${ }^{7}$, o que reflete um longo processo histórico de alijamento desses cidadãos excluídos.

E como podemos repensar a efetividade da porta de acesso e o vislumbre concreto da porta de saída do Poder do Judiciário? Ou seja, que instrumentos há que poderão conferir maior celeridade, eficiência e qualidade à prestação jurisdicional?

Já tratamos do processo e de seus escopos. Seu manejo deve ser tal que atente principalmente para a realização eficaz da justiça substancial e de uma resolução da demanda. Não falamos aqui em pacificação tal como aludido por Dinamarco, mas sim em tratamento do conflito ou resolução daquela parte dele que é levada ao juiz para conhecimento e solução. Esse manejo eficaz deve levar em conta uma reflexão constante entre ativismo judicial versus garantias processuais. Em outro quadrante, o processo deve ser conduzido de forma racional, célere e eficaz sem alijar as garantias processuais constitucionais e em observância a uma coerência e integridade do ordenamento jurídico processual, construído a partir da Constituição Federal.

\section{A TERCEIRA ONDA RENOVATÓRIA DE ACESSO À JUSTIÇA E OS MEIOS CONSENSUAIS DE SOLUÇÃO DE CONFLITOS}

\footnotetext{
${ }^{6}$ Marc Galanter definiu a figura do litigante habitual: algumas espécies de litigantes gozam de uma gama de vantagens estratégicas, como recursos financeiros, que trazem vantagens óbvias. Se o litigante possui recursos, pode suportar as delongas do litígio e essa delonga, inclusive, pode ser uma arma poderosa. Cappelletti: "julgadores passivos, (...), exacerbam claramente esse problema, por deixarem às partes a tarefa de obter $\mathrm{e}$ apresentar as provas, desenvolver e discutir a causa" (1988, p. 21-22).

7 Adriana de Sena Orsini utiliza o termo anomia como "não acesso" à justiça, sem descurar o sentido dado ao termo por Durkheim, referente à quebra das bases normativas, morais e sociais, à ausência de normas. Pondera: "no meu modo de ver, a anomia em maior ou menor grau reflete a confiança do jurisdicionado em face daquele ramo específico do Judiciário e a sua capacidade de dar uma resposta real e efetiva à resolução daquele conflito e de sua forma de ser ou não acessível a esse cidadão" (2014, p. 63).
} 
No desempenho do papel garantidor da democracia e da cidadania, o Poder Judiciário deve perceber o acesso à justiça sob o prisma do jurisdicionado e entender que a garantia do acesso não significa verdadeira realização da justiça. Para tanto, deve o juiz sair do solipsismo e entender não só o direito material que permeia a demanda, mas também compreender a posição dos atores na estrutura e "suas relações simbólicas que perpassam as negociações, acordos, tensões e a posição de cada um, a partir do lugar social que ocupam no campo das relações" (ORSINI, 2014, p. 64).

A população brasileira, acostumada a ter seus conflitos resolvidos pelo Estado, homogeneizada por ideologias que reinaram e calaram seus poderes de participação e enfraqueceram as ações de cidadania, escora-se num Poder Judiciário assoberbado que, mesmo com novos instrumentos para conferir celeridade aos processos, demorará anos para aliviar a taxa de congestionamento. Assim, ajuda a alimentar o paradoxo do acesso à justiça excesso de acesso - não-acesso, ou seja, mais demandas, menos demandas (SADEK, 2014).

Outros caminhos, devem ser percorridos para devolver à sociedade a capacidade de administrar muitos de seus conflitos, deixando para o Judiciário somente aqueles que não puderem ou tiverem como ser resolvidos pelo diálogo, pela construção do consenso, pela participação ativa dos atores no desenho de suas soluções. Leciona Orsini (2014, p. 65) que o desenvolvimento da cultura de paz é realmente um escopo social e processual, todavia

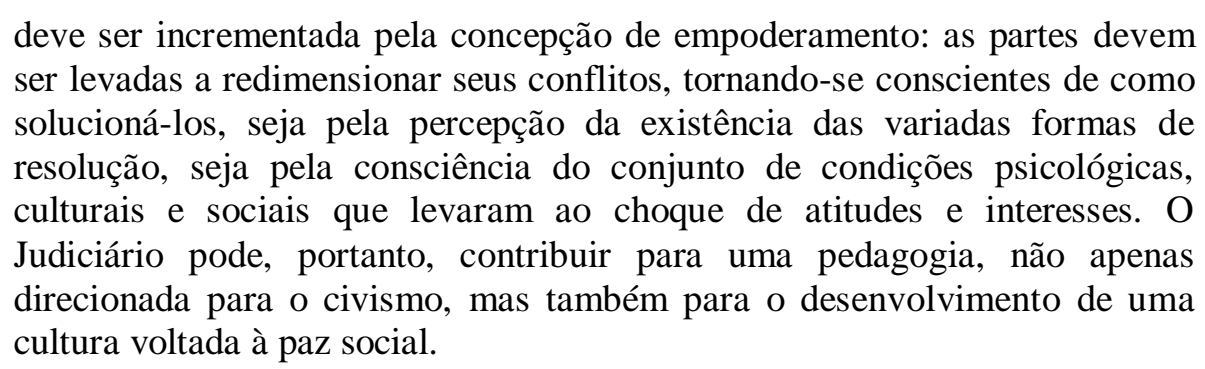

deve ser incrementada pela concepção de empoderamento: as partes devem ser levadas a redimensionar seus conflitos, tornando-se conscientes de como solucioná-los, seja pela percepção da existência das variadas formas de resolução, seja pela consciência do conjunto de condições psicológicas, culturais e sociais que levaram ao choque de atitudes e interesses. $O$ Judiciário pode, portanto, contribuir para uma pedagogia, não apenas direcionada para o civismo, mas também para o desenvolvimento de uma cultura voltada à paz social.

Perseguindo essa missão pedagógica, os operadores do direito deverão reconhecer que o direito, com sua dogmática, não tem resposta para todos os tipos de conflitos contemporâneos, e que por isso é necessário dialogar com outros campos da ciência que podem e devem auxiliar na solução dos litígios. Com essa mentalidade multidisciplinar, os pesquisadores do Projeto Florença repensaram os métodos de resolução de conflitos, que são tratados na chamada terceira onda renovatória de acesso à justiça.

A terceira onda renovatória exige uma abordagem mais compreensiva de reforma, passando a prever novos métodos que tornassem os direitos sociais efetivos. Surge a necessidade de previsão de métodos mais simples, não-adversariais, que não superestimem os 
efeitos de vitórias judiciais, uma vez que os métodos contraditórios não voltam o olhar para o conflito. Torna-se indispensável, frente à complexidade das relações, adaptar os procedimentos à natureza dos conflitos.

Por isso o enfoque da terceira onda leva a uma reflexão e exploração de ampla variedade de reformas, incluindo alteração de procedimentos, mudança de estruturas dos tribunais, criação de novas unidades, especialização, uso de pessoas leigas e profissionais de outras áreas, modificações no direito substantivo destinadas a evitar litígios ou facilitar a sua solução e a utilização de meios privados ou informais de tratamento de conflitos (1988, p. 71). Com o foco mais amplo, que transcende a questão econômica e de representatividade, surge o esforço de reconhecer a necessidade de previsão de métodos mais adequados para a solução harmônica de determinados tipos de conflitos, em que uma solução adjudicatória não se mostraria tão adequada ou mesmo eficiente. Nas palavras de Cappelletti e Garth (1988, p. 72)

as partes que tendem a se envolver em determinados tipos de litígio também devem ser levadas em consideração. Elas podem ter um relacionamento prolongado e complexo, ou apenas contatos eventuais. Já foi sugerido que a mediação ou outros mecanismos de interferência apaziguadora são os métodos mais apropriados para preservar os relacionamentos. As partes, ademais, podem diferir grandemente em poder de barganha, experiência ou outros fatores (...). Quando as relações se tornam tão interdependentes na complexa organização das sociedades pós-industriais, quanto eram nas sociedades primitivas, renasce a necessidade de solução harmônica dos problemas, de modo a preservar as relações, com uma tendência resultante de se evitarem litígios.

Cappelleti ressalta que a conciliação possui vantagens óbvias "tanto para as partes quanto para o sistema jurídico, se o litígio é resolvido sem necessidade de julgamento" (1988, p. 83), considerando sua rapidez, baixo custo e eficiência. Ademais, pontua que "parece que tais decisões são mais facilmente aceitas do que decretos judiciais unilaterais uma vez que eles se fundam em acordo já estabelecido entre as partes" (1988, p. 84), ao contrário da decisão heterocompositiva, que assenta quem tem razão a partir de um olhar retrospectivo, com atribuição de culpa, nos meios consensuais, o terceiro facilitador, mediador ou conciliador, deve preferencialmente olhar para o futuro, para as consequências de não se chegar a um acordo, e auxiliar as partes, que se tornam protagonistas, a encontrarem múltiplas soluções com benefícios mútuos.

Cappelletti faz um interessante apontamento, que é repetidamente acentuado nas doutrinas dos meios autocompositivos: "É significativo que um processo dirigido para a conciliação - ao contrário do processo judicial, que geralmente declara uma parte "vencedora" 
e a outra "vencida" - ofereça uma possibilidade de que a causas mais profundas de um litígio sejam examinadas e restaurado um relacionamento complexo e prolongado" (1988, p. 84).

A reconciliação entre as partes passa a ser, então, uma alternativa à judicialização. A conciliação e mediação, portanto, têm recebido especial atenção como meios alternativos ao Judiciário. Seus métodos e estilos, assim como a diversidade dos conflitos que hoje podem ser resolvidos por esses meios, têm se especializado, havendo indicadores de tipos diferenciados de comportamentos por parte dos terceiros facilitadores e abordagens que viraram verdadeiras escolas de mediação. Todavia deve-se ter cuidado. Não obstante a imensa utilidade desses meios para diversos tipos de demandas e partes, principalmente nos casos de necessidade de se resguardar os relacionamentos subjacentes, não devemos voltar o olhar somente para a finalidade de conferir celeridade e desafogar o Judiciário. Conforme lembra Cappelletti, "devemos certificar-nos de que os resultados representem verdadeiros êxitos, não apenas remédios para problemas do judiciário, que poderiam ter outras soluções" (1988, p, 87).

Em uma democracia substancial, de fundo constitucional, o diálogo interdisciplinar e a abertura da possibilidade de participação dos atores no desenho da solução de seus conflitos são essenciais à função adjudicatória do Poder Judiciário, "na medida em que esse poder passa a tratar de assuntos políticos, como uma espécie de sucedânea do Executivo e do Legislativo" (VAZ, 2016, p. 65), como tratado antes, suprindo vazios. Esses vieses permitem contribuir para a conquista da legitimidade democrática da atuação judicante, que passa pelo "redimensionamento do espaço participativo das partes na solução dos conflitos de interesses" (VAZ, 2016, p. 65).

Nesse ponto, reflete Paulo Afonso Brum Vaz (2016, p. 66) que a legitimidade do Poder Judiciário deve ser "conquistada pela abertura democrática que as estruturas organizacionais e os programas que o sistema possa oferecer aos conflitantes e pelo desempenho do seu papel de garante de direitos fundamentais" ${ }^{8}$. Podemos falar em uma legitimação constitucional, derivada do próprio ordenamento jurídico, que seria uma legitimação formal, e em uma legitimação conferida pelos próprios cidadãos através da participação no procedimento de formação da tutela jurisdicional. Ou seja, essa forma de legitimação da atuação do Judiciário expressa-se "não só pela obrigatoriedade da fundamentação das decisões (em concreto), a participação, a comunicação e o procedimento,

\footnotetext{
${ }^{8}$ Convém observar, com Vaz (2016, p. 66), que o modelo de legitimação do Judiciário deve ir além do "indesejável hiperdimensionamento do caráter procedimental da atuação judiciária (procedimentalismo), e que significa, muito mais, a própria ampliação da condição dos cidadãos pela via da prestação jurisdicional dirigida à tutela dos seus direitos fundamentais".
} 
mas também pelo resultado sensível no plano social que decorre da atuação judicial e a sua abertura às expectativas sociais" (VAZ, 2016, p. 67).

No plano pragmático, portanto, essas novas práticas legitimadoras, principalmente no cenário da concretização dos direitos sociais por meio da judicialização da política, decorrem de estratégias voltadas à justiça social, à participação, à autonomia, ao empoderamento e à emancipação dos cidadãos. Em outras palavras, passam pelo procedimento, que somente terá função legitimante se abrir espaço para a comunicação, para o diálogo participativo dirigido ao consenso, no qual cada interessado (parte) possa aduzir suas pretensões e defender seus pontos de vista, dialética e democraticamente.

\section{PERSPECTIVAS AUTOCOMPOSITIVAS DO DIREITO PROCESSUAL}

Temos, então, a importância da introdução de outros instrumentos no ordenamento jurídico para a composição de conflitos que não o modelo adjudicatório, mas cuja centralidade da resolução esteja na construção do consenso por meio da participação efetiva das partes no diálogo construtivo.

Os meios consensuais são estratégias não só para legitimação da solução mas também para (i) possibilitar um manejo mais adequado de certos tipos de conflitos, (ii) conferir maior efetividade para a solução, uma vez que aquilo que é acordado tem maiores possibilidades de ser cumprido espontaneamente; (iii) contribuir para maior celeridade processual; (iv) reduzir custos da demanda; (v) viabilizar saltos de empoderamento e reconhecimento das partes; (vi) possibilitar reaproximações e até (vii) contribuir para a alteração de padrões dialógicos entre os envolvidos, dado o seu caráter pedagógico.

Kazuo Watanabe conclui que, durante muito tempo, "os métodos informais de solução dos conflitos foram considerados como próprios das sociedades primitivas e tribais, ao passo que o processo jurisdicional representou insuperável conquista da civilização". E reflete que "quando as coisas instituídas falham, por culpa de fatores estranhos a nossa vontade, convém abrir os olhos às lições do passado para verificar se, acaso, com mais humildade, dentro de nossas forças limites, não podem elas nos ensinar a vencer desafios do presente" (2005, p. 684).

Esse volver para o passado, porém, enfrenta obstáculos diversos como a falta de emancipação, as ideologias homogeneizantes, a falta de concretude de direitos sociais. Mas 
seu principal desafio é a cultura litigiosa dos profissionais do direito, acostumados ao jogo processual e à solução adjudicatória.

Contudo, mesmo acostumados a essa cultura beligerante, assistimos a uma mudança paradigmática, da cultura do confronto para outra mais pacificadora, da adjudicação para a autocomposição. Não há como fugir dessa 'terceira onda', que, mesmo a duras penas, deverá plantar as sementes para as transformações dos parâmetros de administração do Judiciário e de emancipação da própria sociedade. Nas palavras de Cappelletti, a onda renovatória que traz os meios consensuais deve incluir a advocacia, judicial e extrajudicial e é imperioso que também dirija sua atenção para o conjunto geral de instituições e mecanismos, pessoas e procedimentos utilizados para processar e mesmo prevenir disputas nas sociedades modernas (1988, p. 52).

No Brasil, cumpre registrar que a inclusão desses novos instrumentos de resolução de disputas no ordenamento jurídico processual teve como março a implementação da Política Judiciária de Tratamento Adequado dos Conflitos (Resolução 125/2010 do Conselho Nacional de Justiça), reforçando-se sobremaneira com a Lei de Mediação (Lei nº 13.140/2015) e com o Código de Processo Civil.

De todo modo, independentemente de ser extra ou endoprocessual, o ponto culminante na institucionalização desses meios consensuais é a democratização do sistema de justiça e a descentralização do lócus de solução dos dissensos e a substituição paulatina da cultura da litigância para uma cultura da cooperação, do diálogo e do entendimento. Nesse ponto, temos uma certa superação do paradigma monopolístico do Judiciário na solução das controvérsias.

\section{CONCLUSÃO}

Ao contrário do cenário positivista e dogmático imperante até a segunda guerra, hoje assistimos a uma onda renovatória dos meios de solução de conflitos mais compatíveis com a complexidade das relações sociais e dos novos direitos emergentes após a década de 1950. A diminuição dos formalismos processuais, assim como ideias de simplicidade, celeridade, economicidade e do acesso à Justiça são imperativos.

Nesse ponto, como exposto nesse trabalho, o processo gradual de judicialização das relações sociais levou à necessidade de expandir o campo de atuação do Poder Judiciário, abrandando o sistema de neutralidade, que passou gradualmente a ser substituído por um 
maior ativismo judicial, visando à maximização de oportunidades para que o resultado seja justo e não reflita apenas as desigualdades entre as partes. Essa postura mais ativista é fruto do fortalecimento das democracias, que pressupõe uma efetividade na tutela dos direitos fundamentais e sociais e uma atuação do Judiciário para além da aplicação dogmática da lei ao caso concreto, isso porque foi preciso que a jurisdição preenchesse espaços vazios deixados pela falta de emancipação da sociedade brasileira após décadas de opressão e pelos novos papéis que precisou assumir. O Estado, pois, precisou redesenhar o acesso à justiça, adotando o compromisso com o movimento de abertura de acesso e garantindo, ao mesmo tempo, a potencialização do processo enquanto instância capaz de conferir efetividade aos direitos, em razão da judicialização das relações sociais.

A abertura ao acesso e o processo de democratização fez com que o Judiciário assistisse a um aumento considerável dos litígios, não somente em razão de circunstâncias como facilitação e gratuidade do acesso, na esteira da primeira onda renovatória de Cappelletti, mas principalmente em decorrência de fatores como a inobservância, pelo próprio Estado, das normas constitucionais programáticas; a falta de efetividade das políticas públicas garantidoras de direitos sociais; a própria demora no deslinde dos processos, estimulando a litigiosidade por parte dos litigantes habituais; o descumprimento sistemático da lei, pelo Estado e pelas organizações. Esse excesso de acesso, em verdade, e como foi tratado no corpo deste trabalho, descamba para a ausência de acesso para parcela da população que realmente precisa do Judiciário para que seus direitos fundamentais sejam reconhecidos e garantidos.

$\mathrm{Na}$ esteira dessa busca por maior efetividade, legitimidade e eficiência processual ressurgem os meios consensuais de solução dos conflitos, realocados da ancestralidade para o campo do direito processual e matizado por novas teorias sociais, cuja interferência na ciência do direito é hoje possível em razão da complexidade da sociedade e das relações, que fazem com que a lógica binária e adjudicatória positivista não mais satisfaçam os anseios por soluções mais adequadas para os conflitos.

Portanto, com a Política Judiciária Nacional de tratamento adequado às demandas, o processo passa a servir como meio de efetivação dos direitos, permeado por técnicas advindas de outras ciências e permitindo que as próprias técnicas processuais sirvam às funções sociais. Ademais, o Poder Judiciário passa a não ser mais a única arena para a resolução dos conflitos, permitindo a adoção e o encorajamento de alternativas ao sistema judiciário formal. Esse movimento encontra total consonância com a conhecida terceira onda renovatória de acesso à justiça. Pelos métodos autocompositivos, pois, abrem-se caminhos para a busca da 
pacificação, da participação efetiva das partes no desenho da solução de suas controvérsias, da emancipação, do tratamento mais harmonizador dos conflitos e para a eficácia e concretização mais célere dos direitos sociais.

Podemos considerar a mediação e a conciliação como lócus de democrático de resolução de conflitos e de escuta e apoio ao desenvolvimento da alteridade e respeito. São ideais que devem ser perseguidos por meio de políticas que atinjam não só o Judiciário, mas deverá expandir-se por toda a sociedade, eis que passam por uma necessária mudança de mentalidade e cultura. Concluindo, os meios consensuais de tratamento dos dissensos podem ser considerados como vetores de legitimidade para a própria Justiça, exercendo a um só tempo um importante papel de arena de inclusão e reconhecimento e de efetivação dos direitos fundamentais.

\section{BIBLIOGRAFIA}

CAPPELLETTI, Mauro, e Bryant GARTH. Acesso à Justiça. Tradução: Ellen Gracie Northfleet. Porto Alegre: Sérgio Antônio Fabris, 1988.

DINAMARCO, Cândido Rangel. A instrumentalidade do processo. 11 ed. São Paulo: Malheiros, 2003.

HABERMAS, Jürgen. Direito e democracia: entre facticidade e validade. $2^{\mathrm{a}}$. Tradução: Flávio Beno Siebeneichler. Vol. I. Rio de Janeiro: Tempo Brasileiro, 2003.

ORSINI, Adriana Goulart de Sena. Judicialização das relações sociais e desigualdade de acesso: por uma reflexão crítica. In: Justiça do Século XXI. ORSINI, Adriana Goulart de Sena (Coord.); COSTA, Mila Batista Leite Corrêa da (Coord.); ANDRADE, Oyama Karyna Barbosa (Coord.). São Paulo: LTr, 2014.

SADEK, Maria Tereza. Acesso à justiça: um direito e seus obstáculos. São Paulo: Revista USP, n. 101, 2014. Disponível em:<http://www.revistas.usp.br/revusp/article/view/87814>. Acesso em 13/04/2017.

SANTOS, Boaventura de Souza. Democratizar a democracia: os caminhos da democracia participativa. Boaventura de Sousa Santos, organizador. Rio de Janeiro: Civilização Brasileira, 2002.

TUCCI, José Rogério Cruz e. Lineamentos da nova reforma do CPC. $2^{\mathrm{a}}$. São Paulo: Revista dos Tribunais, 2002.

VAZ, Paulo Afonso Brum. Juizado Especial Federal: contributo para um modelo democrático de justiça conciliativa. Brasília: Conselho da Justiça Federal, Centro de Estudos Judiciários, 2016. 
VIANNA, Luiz Werneck; BURGOS, Marcelo Baumann; CARVALHO, Maria Alice Rezente; melo; MELO, Manuel Palacio Cunha. A judicialização da política e das relações sociais no Brasil. São Paulo: Revan. 1999.

VIANNA, Luiz Werneck; BURGOS, Marcelo Baumann, SALLES, Paula Martins. Dezessete anos de judicialização da política. Disponível em: <http://www.scielo.br/pdf/ts/v19n2/a02v19n2> (acesso em 17 de 05 de 2017).

WATANABE, Kazuo. Cultura da sentença e cultura da pacificação. In: YARSHELL, Flávio Luiz; MORAES, Maurício Zanoide de. Estudos em homenagem à professora Ada Pelegrini Grinover. São Paulo: DPJ Editora, 2005. 